\title{
Frequency Analysis of Electromagnetic Waves in Tripartite Photonic Crystals with Adjustable Part Lengths
}

\author{
Ayse Nihan Basmaci ${ }^{1 *}$ \\ ${ }^{1 *}$ Tekirdag Namik Kemal University, Vocational School of Technical Sciences, Electronics and Automation Department, Tekirdag, Turkey (ORCID: 0000-0003-3737- \\ 3751), anbasmaci@nku.edu.tr
}

(International Symposium on Multidisciplinary Studies and Innovative Technologies (ISMSIT) 2021 - 21-23 October 2021)

(DOI: 10.31590/ejosat.1019961)

ATIF/REFERENCE: Basmaci, A. N. (2021). Frequency Analysis of Electromagnetic Waves in Tripartite Photonic Crystals with Adjustable Part Lengths. European Journal of Science and Technology, (29), 311-316.

\begin{abstract}
In this study, electromagnetic wave propagation frequencies are investigated in four different photonic crystal structures, three of which are tripartite and one of which is bipartite. In addition, the effects of part lengths and material property parameters $(\varepsilon, \mu)$ of these structures on electromagnetic wave frequencies are examined. The photonic crystal structures are one-dimensional (1D) and the parts of these structures have different lengths. Differences in the part lengths allow the electromagnetic wave frequencies to be adjusted. The material property parameters of each part of the photonic crystal structures change in the $\mathrm{x}$-axis direction and the default values of these parameters theoretically change from 1 to 2 . The values for the first three modes of electromagnetic wave frequencies obtained for four different photonic crystal structures are different from each other. The lowest values of the electromagnetic wave frequencies are obtained for the first photonic crystal structure (S1) with the shortest first and second part lengths.
\end{abstract}

Keywords: Electromagnetic wave, Frequency analysis, Maxwell's equations, Photonic crystals.

\section{Ayarlanabilir Parça Uzunluklarına Sahip 3-Parçalı Fotonik Kristallerde Elektromanyetik Dalgaların Frekans Analizi}

Öz

Bu çalışmada, üçü 3-parçalı ve biri 2-parçalı olmak üzere dört farklı fotonik kristal yapıda elektromanyetik dalga yayılımı frekansları incelenmektedir. Ayrıca, bu yapıların parça uzunluklarının ve malzeme özelliği parametrelerinin $(\varepsilon, \mu)$ elektromanyetik dalga frekansları üzerindeki etkileri araştırılmaktadır. Fotonik kristal yapılar tek boyutlu (1D) olup bu yapılara ait parçalar farklı uzunluklara sahiptir. Parça uzunluklarındaki farklılıklar elektromanyetik dalga frekanslarının ayarlanabilmesine olanak sağlamaktadır. Fotonik kristal yapıların her bir parçasının malzeme özelliği parametreleri x-ekseni doğrultusunda ve bu parametrelerin varsayılan değerleri teorik olarak 1'den 2'ye doğru değer alacak biçimde değişmektedir. Dört farklı fotonik kristal yapı için elde edilen elektromanyetik dalga frekanslarının ilk üç moduna ilişkin değerler birbirinden farklıdır. Elektromanyetik dalga frekanslarının en düşük değerleri, en kısa birinci ve ikinci parça uzunluğuna sahip birinci fotonik kristal yapı (S1) için elde edilmektedir.

Anahtar Kelimeler: Elektromanyetik dalga, Frekans analizi, Maxwell denklemleri, Fotonik kristaller.

\footnotetext{
* Corresponding Author: Tekirdag Namik Kemal University, Vocational School of Technical Sciences, Electronics and Automation Department, Tekirdag, Turkey, ORCID: 0000-0003-3737-3751, anbasmaci@nku.edu.tr
} 


\section{Introduction}

Due to the fast technological advances in optoelectronics, optics, and telecommunications, studies on optical structures have gained momentum (Barrientos-Garcia et al., 2016; Li et al., 2016; Han et al., 2021; Kaburcuk and Elsherbeni, 2021). There are many studies in the literature on optical structures, such as metamaterials and photonic crystals (Sung et al., 2011; AlipourBanaei et al., 2017; Chen et al., 2017; Zhang et al., 2018; Benhaddad et al., 2019; Napolskii et al., 2020; Shi et al., 2020; Singer et al., 2020). Phononic structures affected by sound waves also show structurally similar properties to photonic crystals among optical structures (Lu et al., 2017; Sun et al., 2019; Ayman et al., 2020; Rostami et al., 2020; Trzaskowska et al., 2020; Rostami et al., 2021).

Photonic crystals are formed artificially by arranging layers with different material property parameters $(\varepsilon, \mu)$ end-to-end or side by side along certain axes (Busch et al., 2007; Ginn and Brener, 2012; Moitra et al., 2014). In order to analyze the behaviors of electromagnetic wave propagation in photonic structures, each layer's electromagnetic wave propagation behavior in the periodic layer group forming the structures should be considered separately. In the literature, there are many studies that theoretically examine the electromagnetic wave propagation behavior occurring in each layer of one-dimensional photonic structures (Delihacıoğlu, 2014; Kaya and Delihacioglu, 2014; Kang et al., 2018; Hassan et al., 2019; Dukata and Waldemar, 2020), as well as experimental studies in which these structures are manufactured using various production methods (Chung et al., 2010; Askari et al., 2020; Gao et al., 2020; Bi et al., 2021; Wei et al., 2021).

Many studies in the literature guide the solution of the partial differential equation regarding the electromagnetic wave propagation obtained by using Maxwell's equations to determine the behavior of electromagnetic wave propagation in optical structures (Qi et al., 2010; Shramkova and Olkhovskiy, 2011; Khanikaev et al., 2012; Jahani and Jacob, 2016; Lee et al., 2017; Meng et al., 2019; Wang et al., 2019; Basmaci, 2020; Kaburcuk et al., 2020; Sener and Eker, 2020). For instance, in (Basmaci, 2020), wave dispersion relations regarding electromagnetic wave propagation in each layer in photonic waveguides consisting of four different layers, and transmission rates and energies of electromagnetic waves for each layer are examined.

In this study, electromagnetic wave propagation frequencies in four different, one-dimensional (1D) photonic crystal structures, three of which are tripartite and one of which are bipartite, are investigated. Besides, the effects of the photonic crystal structures' part lengths on electromagnetic wave frequencies are examined. The photonic crystals are classified into six different groups according to their parts' material property parameters $(\varepsilon, \mu)$. In these groups, the default material property parameter value for each part changes from 1 to 2 theoretically. Electromagnetic wave frequencies are obtained by considering tripartite and bipartite photonic crystals as a whole by using Maxwell's equations. Unlike other studies in the literature, this study allows the electromagnetic wave frequencies to be adjusted by adjusting the part lengths of tripartite and bipartite photonic crystal structures.

\section{Theoretical Analysis}

The second-order linear partial differential equation regarding electromagnetic wave propagation in a onedimensional (1D) photonic crystal is obtained by using Maxwell's equations.

Figure 1 illustrates a one-dimensional homogeneous photonic crystal.

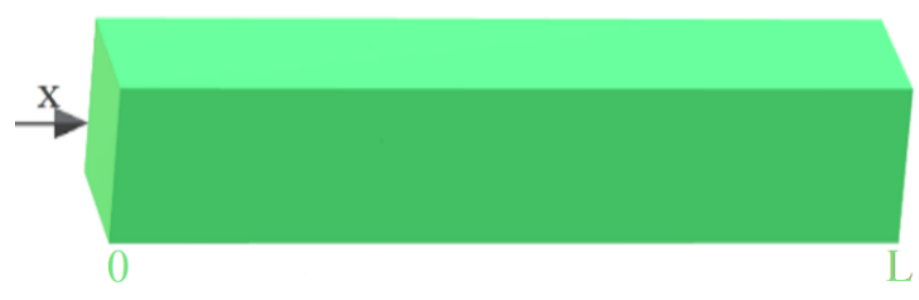

Figure 1. 1D photonic crystal structure

In order to obtain the equation of electromagnetic wave propagation in the photonic crystals, Maxwell's equations are used as in the following forms (Pozar, 2012):

$$
\begin{gathered}
\nabla \cdot \vec{E}=\frac{\rho}{\varepsilon} \\
\nabla \cdot \vec{H}=0 \\
\nabla \times \vec{E}=-i \omega \mu \vec{H} \\
\nabla \times \vec{H}=-i \omega \varepsilon \vec{E}
\end{gathered}
$$

where $\rho$ is the charge density, $\varepsilon$ is the permittivity, $\mu$ is the permeability, $E$ is the electrical field, $H$ is the magnetic field, $i$ is the imaginary number $(i: \sqrt{-1}$ and, $\omega$ is the frequency of the electromagnetic wave.

Using Equation (1c) and Equation (1d), the 1D electromagnetic wave propagation equation is obtained as follows:

$$
\frac{\partial^{2} H(x, t)}{\partial x^{2}}-\mu \varepsilon \frac{\partial^{2} H(x, t)}{\partial t^{2}}=0
$$

where $H(x, t)$ and $(\mu \varepsilon)$ represent the magnetic field and material property parameter, respectively. The material property parameter $(\mu \varepsilon)$ can be briefly defined as $\alpha$.

In order to solve Equation (2), $H(x, t)=w(x) e^{-i \omega t}$ transformation is used. Using this transformation, Equation (3) is obtained as follows:

$$
\frac{\partial^{2} w(x)}{\partial x^{2}}+\mu \varepsilon \omega^{2} w(x)=0
$$

where $w(x)$ represents electromagnetic wave.

Figure 2 depicts a photonic crystal structure consisting of three different optical parts. As can be seen from the figure, both the $\mathrm{x} 1$ and $\mathrm{x} 2$ lengths of the structure and the material property parameters $(\alpha)$ of each part can be adjusted. The material property parameter of Part I is defined by $\alpha$, and the material property parameters of Part II and Part III are defined by $(\alpha \beta)$ and $(\alpha \beta \gamma)$, respectively. In order to obtain electromagnetic wave (EMW) frequencies for the tripartite photonic crystal structure seen in Figure 2, Equation 3 needs to be solved separately for three different parts of the structure. 


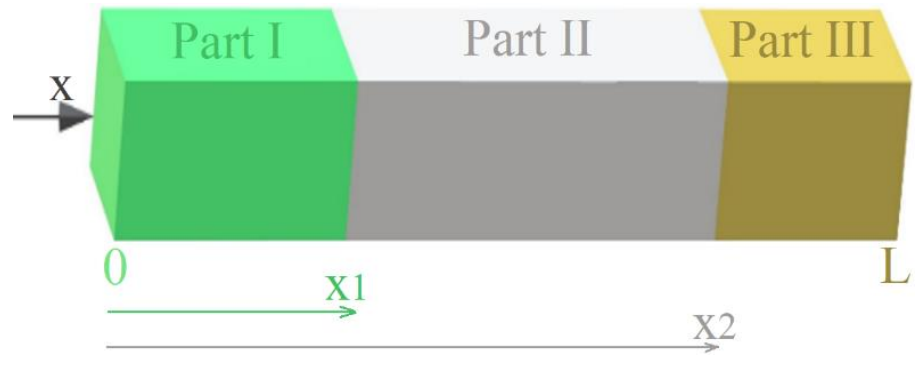

Figure 2. Tripartite, $1 D$ photonic crystal structure

The boundary conditions required to solve Equation 3 are as follows:

$$
\begin{aligned}
w & =0, \text { for } x=0 \text { and } x=L \\
w 1(x) & =w 2(x) \text { and } \frac{\partial w 1(x)}{\partial x}=\frac{\partial w 2(x)}{\partial x}, \text { for } x=x 1 \\
w 2(x) & =w 3(x) \text { and } \frac{\partial w 2(x)}{\partial x}=\frac{\partial w 3(x)}{\partial x}, \text { for } x=x 2
\end{aligned}
$$

where $w 1(\mathrm{x}), w 2(\mathrm{x})$, and $w 3(\mathrm{x})$ represent electromagnetic waves belonging to Part I, Part II, and Part III in the photonic crystal structure, respectively. Accordingly, the nontrivial solution obtained when Equation 3 is solved according to the boundary conditions is as follows:

$$
\left|\left[\begin{array}{cccc}
A 11 & A 21 & A 31 & 0 \\
B 11 & B 21 & B 31 & 0 \\
0 & C 21 & C 31 & C 41 \\
0 & D 21 & D 31 & D 41
\end{array}\right]\right|=0
$$

where A11 and B11 are the coefficients expressing the left side of Part I; A21, A31, B21, and B31 are the coefficients expressing the left side of Part II. C21, C31, D21, and D31 are coefficients expressing the left side of Part III, while C41 and D41 are coefficients expressing the right side of Part III. The coefficients can be clearly written as in the following forms:

$$
\begin{aligned}
& A 11=i \sin (\alpha \omega x 1) \\
& A 21=-i \sin (\alpha \beta \omega x 1) \\
& A 31=-\cos (\alpha \beta \omega x 1) \\
& B 11=i \alpha \cos (\alpha \omega x 1) \\
& B 21=-i \alpha \beta \cos (\alpha \beta \omega x 1) \\
& B 31=i \alpha \beta \sin (\alpha \beta \omega x 1) \\
& C 21=i \sin (\alpha \beta \omega x 2) \\
& C 31=\cos (\alpha \beta \omega x 2)
\end{aligned}
$$

$C 41=-i \sin (\alpha \beta \gamma \omega x 1)+i \tan (\alpha \beta \gamma \omega L) \cos (\alpha \beta \gamma \omega x 2)$

$$
\begin{gathered}
D 21=i \alpha \beta \cos (\alpha \beta \omega x 2) \\
D 31=-\alpha \beta \sin (\alpha \beta \omega x 2) \\
D 41=-i \alpha \beta \gamma \cos (\alpha \beta \gamma \omega x 2)- \\
i \alpha \beta \gamma \tan (\alpha \beta \gamma \omega L) \sin (\alpha \beta \gamma \omega x 2)
\end{gathered}
$$

It should be noted that the coefficients given in Equations (6a61) can be adjusted using the part lengths $\mathrm{x} 1$ and $\mathrm{x} 2$ of the photonic crystal structure.

\section{Results and Discussion}

In this study, electromagnetic wave propagation frequencies are investigated in four different photonic crystal structures, three of which are 3-part and one of which is 2-part. These photonic crystal structures are named based on their $\mathrm{x} 1$ and $\mathrm{x} 2$ lengths. The first structure, named $\mathrm{S} 1$ is $\mathrm{x} 1: 0.1 \mathrm{~L}$ and $\times 2: 0.2 \mathrm{~L}$ length, the second structure, named $\mathrm{S} 2$ is $\times 1: 0.333 \mathrm{~L}$ and $\times 2: 0.333 \mathrm{~L}$ length, the third structure, named $\mathrm{S} 3$ is $\times 1: 0.8 \mathrm{~L}$ and $\mathrm{x} 2: 0.9 \mathrm{~L}$ length, respectively. The fourth structure named S4, consists of two equal-length parts.

These photonic crystal structures will be examined in six different groups defined according to material property parameters. The material property parameters of these six different groups are given in order $(\alpha, \beta, \gamma)$. Accordingly, the material property parameters of the first group (Group 1), the second group (Group 2), the third group (Group 3), the fourth group (Group 4), the fifth group (Group 5), and the sixth group (Group 6) are defined as $(1,1,1),(1,2,1),(1,1,2),(1,1.5,1.3)$, $(1,1.3,1.5)$ and $(2,1,1)$, respectively. The material property parameters of these six groups are also shown in Table 1.

Table 1. The material property parameters of the $1 D$ tripartite photonic crystal for six different groups

\begin{tabular}{c|ccc}
\hline Groups & Part I & Part II & Part III \\
\hline $\mathbf{1}$ & 1 & 1 & 1 \\
$\mathbf{2}$ & 1 & 2 & 2 \\
$\mathbf{3}$ & 1 & 1 & 2 \\
$\mathbf{4}$ & 1 & 1.5 & 2 \\
$\mathbf{5}$ & 1 & 1.3 & 2 \\
$\mathbf{6}$ & 2 & 2 & 2 \\
\hline
\end{tabular}

The electromagnetic wave frequencies of the four photonic crystal structures named S1, S2, S3, and S4, whose material property parameters are given in Table 1, are shown in Figures 3 6.

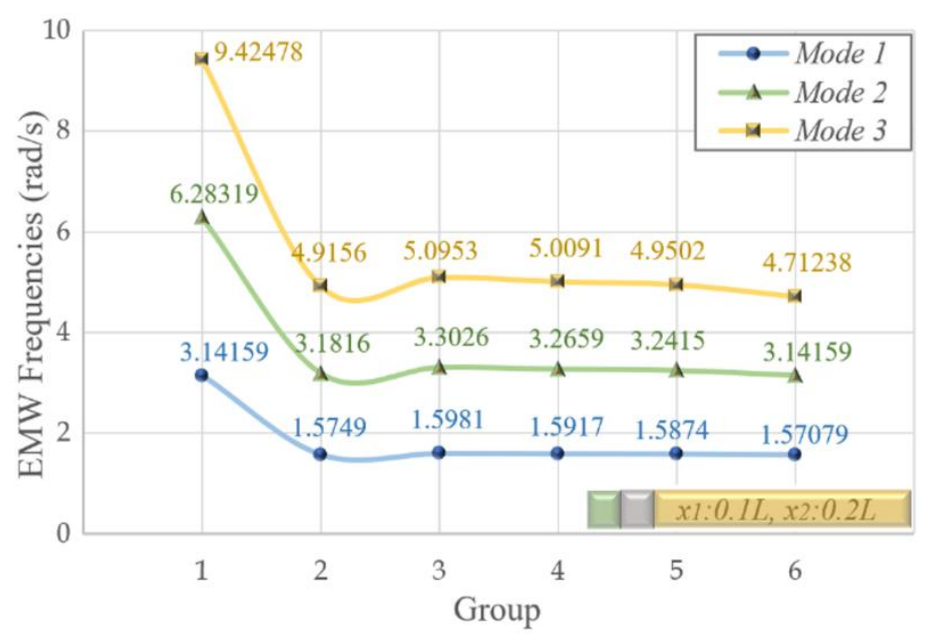

Figure 3. EMW frequencies of S1 for six different groups

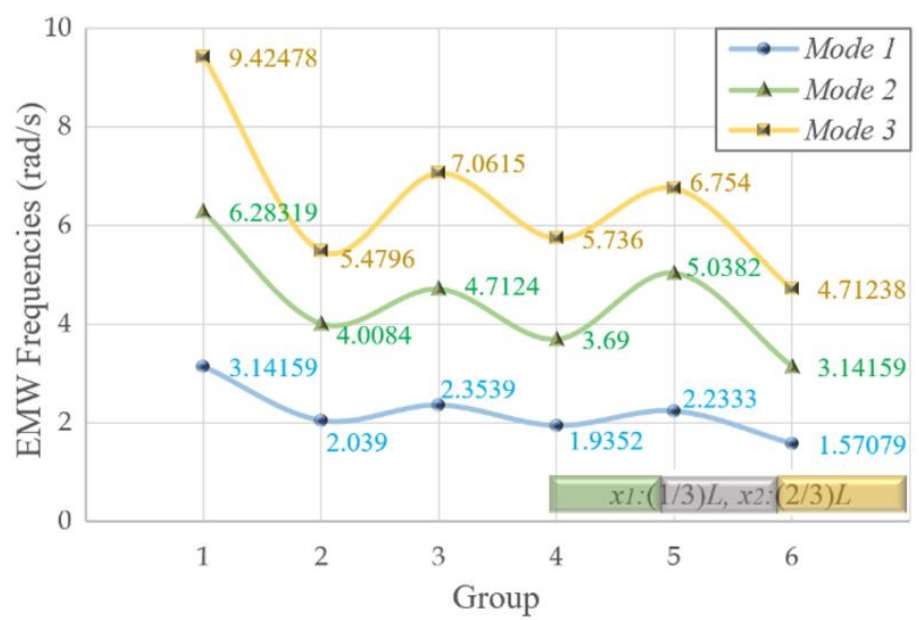

Figure 4. EMW frequencies of S2 for six different groups 


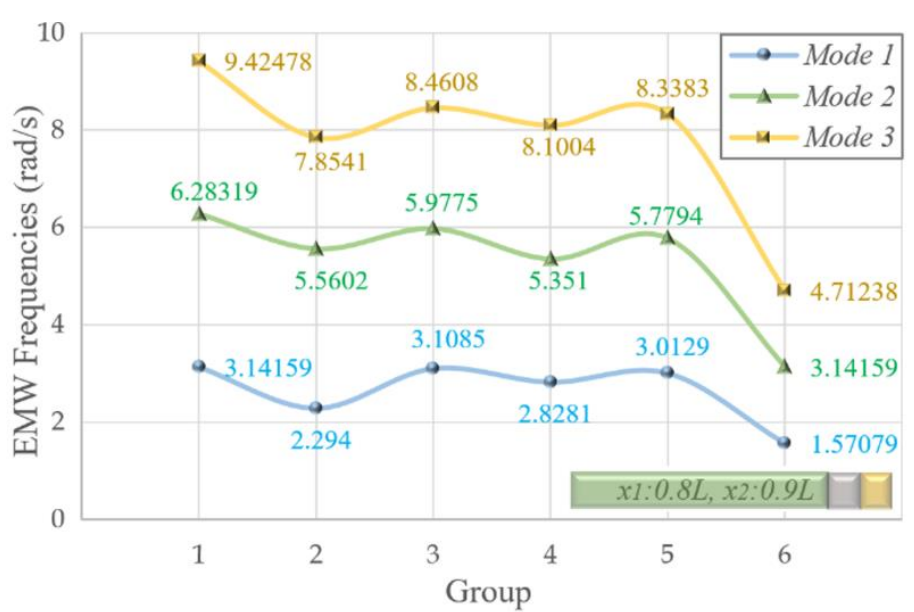

Figure 5. EMW frequencies of S3 for six different groups

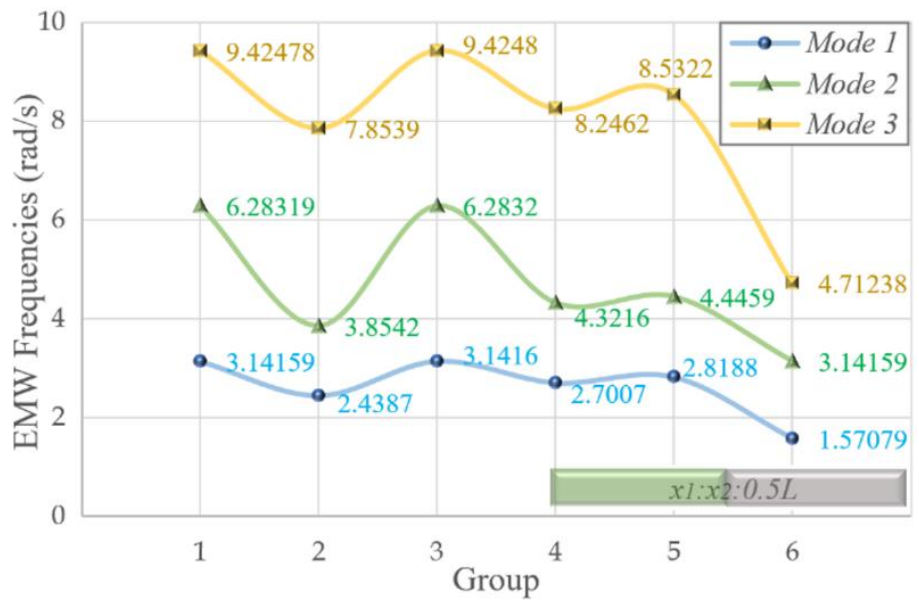

Figure 6. EMW frequencies of S4 for six different groups

It should be noted that the highest frequencies of electromagnetic waves are obtained for the values of material parameters given in Group 1, while the lowest frequencies are obtained for the material parameters' values given in Group 6. In addition, the highest electromagnetic wave frequency values are obtained for the photonic crystal structure named S4 consisting of two equal-length parts, while the lowest electromagnetic wave frequency values are obtained for the photonic crystal structure named $\mathrm{S} 1$ whose part lengths are $0.1 \mathrm{~L}$ and $0.2 \mathrm{~L}$, respectively.

\section{Conclusion}

In this study, electromagnetic wave propagation frequencies are investigated in four different photonic crystal structures, three of which are 3-part and one of which is 2-part. In addition, the effects of part lengths and material property parameters $(\varepsilon, \mu)$ of these structures on electromagnetic wave frequencies are investigated. Unlike other studies in the literature, this study allows tuning of electromagnetic wave frequencies by adjusting the part lengths of tripartite and bipartite photonic crystal structures. The material property parameters of each part of the photonic crystal structures change in the $\mathrm{x}$-axis direction and the default values of these parameters theoretically change from 1 to 2. It should be noted that the highest EMW frequency values are obtained for the photonic crystal structure named S4, which consists of two pieces of equal length, and the lowest EMW frequency values are obtained for the photonic crystal structure named S1 with part lengths of $0.1 \mathrm{~L}$ and $0.2 \mathrm{~L}$. Moreover, the highest frequency values of electromagnetic waves are obtained for the values of material parameters given in Group 1, while the lowest frequency values are obtained for the material parameters' values given in Group 6.

In future studies, the analysis applied to one-dimensional photonic crystal structures within the scope of this study can also be applied to two-dimensional and three-dimensional photonic crystal structures.

\section{References}

Alipour-Banaei, H., Serajmohammadi, S. \& Mehdizadeh, F. (2017). All optical NAND gate based on nonlinear photonic crystal ring resonators. Optik, 130, 1214-1221.

http://dx.doi.org/10.1016/j.ijleo.2016.11.190

Askari, M., Hutchins, D., Thomas, P. J., Astolfi, L., Watson, R. L., Abdi, M., Ricci, M., Laureti, S., Nie, L., Freear, S., Wildman, R., Tuck, C., Clarke, M., Woods, E., \& Clare, A. T. (2020). Additive manufacturing of metamaterials: A review, Additive Manufacturing, 36, 101562.

http://dx.doi.org/10.1016/j.addma.2020.101562

Ayman, A., Prasad S. \& Singh V. (2020). Tuning the band structures and electromagnetic density of modes in fused Silica slab by acoustic waves, Optik - International Journal for Light and Electron Optics, 204, 164105.

http://dx.doi.org/10.1016/j.ijleo.2019.164105

Barrientos-Garcia, A., Sukhoivanov, I. A., Andre-Lucio, J. A., Hernandez-Garcia, J. C.., Ramos-Ortiz, G., Ibarra-Manzano, O. G., \& Guryev, I. V. (2016). Numerical analysis of supercontinuum generation in photonic-crystal fibers with zero dispersion wavelengths in telecommunication windows, Optik, 127, 10981-10990.

https://doi.org/10.1016/j.ijleo.2016.08.111

Basmaci, A. N. (2020). Characteristics of electromagnetic wave propagation in a segmented photonic waveguide, Journal of Optoelectronics and Advanced Materials, 22, 452-460.

Benhaddad, M., Kerrour, F., Benabbes O., \& Saouli, A. (2019). A new photonic crystal fibre with low nonlinearity, low confinement loss and improved effective mode area, Ukrainian Journal of Physical Optics, 20, 47-53.

https://doi.org/10.3116/16091833/20/2/47/2019

Bi, K., Wang, Q., Xu, J., Chen, L., Lan C., \& Lei, M. (2021). Alldielectric metamaterial fabrication techniques, Advanced Optical Materials, 9, 2001474.

https://doi.org/10.1002/adom.202001474

Busch, K., Freymann, G., Linden, S., Mingaleev, S. F., Tkeshelashvili, L. \& Wegener, M. (2007). Periodic nanostructures for photonics. Physics Reports, 444, 101-202.

https://doi.org/10.1016/j.physrep.2007.02.011

Chen, X.-D., Zhao, F.-L., Chen, M. \& Dong, J.-W. (2017). Valley-contrasting physics in all-dielectric photonic crystals: Orbital angular momentum and topological propagation," Physical Review B, 96, 020202(R).

Chung, K. H., Kato, T., Mito, S., Takagi, H., \& Inoue, M. (2010). Fabrication and characteristics of one-dimensional magnetophotonic crystals for magneto-optic spatial light phase modulators, Journal of Applied Physics, 107, 09A930.

Delihacıŏlu, K. (2014). Chiral frequency selective surfaces comprised of multiple conducting strips per unit cell, IET Microwaves, Antennas \& Propagation, 8, 621-626.

https://doi.org/10.1049/iet-map.2013.0146

Dukata, A., \& Waldemar, S. (2020). Transmission parameters of an anisotropic layered structure in the waveguide, SPIE Conference Proceedings, 11442, 114420A-1 - 114420A-17.

https://doi.org/10.117/12.2565584 
Gao, T., Sun, H., Hong, Y., \& Qing, X. (2020). Hidden corrosion detection using laser ultrasonic guided waves with multifrequency local wavenumber estimation, Ultrasonics, 108, 106182.

https://doi.org/10.1016/j.ultras.2020.106182

Ginn, J. C. \& Brener, I. (2012). Realizing optical magnetism from dielectric metamaterials, Physical Review Letters, 108, 097402.

https://doi.org/10.1103/PhysRevLett.108.097402

Han, Y., Fei, H., Lin, H., Zhang, Y., Zhang, M., \& Yang, Y. (2021). Design of broadband all-dielectric valley photonic crystals at telecommunication wavelength, Optics Communications, 488, 126847.

https://doi.org/10.1016/j.optcom.2021.126847

Hassan, S., Alnasser, K., Lowell, D., \& Lin, Y. (2019). Effects of photonic band structure and unit super-cell size in graded photonic super-crystal on broadband light absorption in silicon, Photonics, 6, 50.

https://doi.org/10.3390/photonics6020050

Jahani, S., \& Jacob, Z. (2016). All-dielectric metamaterials, Nature Nanotechnology, 11, 23-36.

https://doi.org/10.1038/nnano.2015.304

Kaburcuk, F., \& Elsherbeni, A. Z. (2021). Efficient analysis of a dispersive headmodel due to smart glasses embedded antennas at $\mathrm{Wi}-\mathrm{Fi}$ and $5 \mathrm{G}$ frequencies, Applied Computational Electromagnetics Society Journal, 36, 159167.

https://doi.org/10.47037/2020aces.j.360207

Kaburcuk, F., Elsherbeni, A. Z., Lumnitzer, R., \& Tanner, A. (2020). Electromagnetic waves interaction with a human head model for frequencies up to $100 \mathrm{GHz}$, Applied Computational Electromagnetics Society Journal, 35, 613621.

Kang, Y., Liu, H., \& Cao, Q. (2018). Enhanced absorption in heterostructure composed of graphene and a doped photonic crystals, Optoelectronics and Advanced Materials - Rapid Communications, 12, 665-669.

Kaya, N., \& Delihacioglu, K. (2014). Reflection and transmission coefficients from chiral nihility slab, Journal of Optoelectronics and Advanced Materials, 16, 859-863.

Khanikaev, A. B., Mousavi, S. H., Wu, C., Dabidian, N., Alici, K. B., \& Shvets, G. (2012). Electromagnetically induced polarization conversion, Optics Communications, 285, 34233427.

https://doi.org/10.1016/j.optcom.2012.03.023

Lee, D., Nguyen, D. M., \& Rho, J. (2017). Acoustic wave science realized by metamaterials, Nano Convergence, 4, 1-15.

https://doi.org/10.1186/s40580-017-0097-y

Li, K., Lim, J. L., Xu, Z., Hu, D. J. J., Wong, R. Y.-N., Shum, P. P., Hao, E. J., Wang, Y., Sun, Q., \& Jiang, M. (2016). Investigation of temperature sensitivity under the influence of coupling strength between a silica core and a satellite waveguide in a photonic crystal fiber with selective infiltration of glycerin, Procedia Engineering, 140, 72-76.

https://doi.org/10.1016/j.proeng.2015.08.1115

Lu, J., Qiu, C., Ye, L., Fan, X., Ke, M., Zhang F., \& Liu, Z. (2017). Observation of topological valley transport of sound in sonic crystals, Nature Physics, 13, 369-375.

https://doi.org/10.1038/nphys3999

Meng, F., Du, L., Yang, A., \& Yuan, X. (2019). Low loss surface electromagnetic waves on a metal-dielectric waveguide working at short wavelength and aqueous environment, Optics Communications, 433, 10-13. https://doi.org/10.1016/j.optcom.2018.09.063

Moitra, M., Slovick, B. A., Yu, Z. G., Krishnamurthy, S. \& Valentine, J. (2014). Experimental demonstration of a broadband all-dielectric metamaterial perfect reflector, Applied Physics Letters, 104, 171102.

https://doi.org/10.1063/1.4873521

Napolskii, K. S., Noyan, A. A., \& Kushnir, S. E. (2020). Control of high-order photonic band gaps in one-dimensional anodic alumina photonic crystals, Optical Materials, 109, 110317.

https://doi.org/10.1016/j.optmat.2020.110317

Pozar, D. M. (2012). Microwave Engineering $4^{\text {th }}$ Edition, John Wiley \& Sons, Inc. Amherst, Massachusetts.

Qi, L., Yang, Z., Lan, F., Gao, X. \& Shi, Z. (2010). Properties of obliquely incident electromagnetic wave in one-dimensional magnetized plasma photonic crystals, Physics of Plasmas, 17, 042501 .

Rostami, A., Kaatuzian, H., \& Rostami-Dogolsara, B. (2020). Acoustic 1 x 2 demultiplexer based on fluid-fluid phononic crystal ring resonators, Journal of Molecular Liquids, 308, 113144.

https://doi.org/10.1016/j.molliq.2020.113144

Rostami, A., Kaatuzian, H., \& Rostami-Dogolsara, B. (2021). Design and analysis of tunable acoustic channel drop filter based on fluid-fluid phononic crystal ring resonators, Wave Motion, 101, 102700.

https://doi.org/10.1016/j.wavemoti.2020.102700

Sener, U. S. \& Eker, S. (2020). Microwave non-destructive testing technique for material characterization of concrete structures via electromagnetic waves with FDTD, Applied Computational Electromagnetics Society Journal, 35, 13901391.

https://doi.org/10.23919/ACES49320.2020.9196177

Shramkova, O. V. \& Olkhovskiy, Y.A. (2011). Electromagnetic wave transmission and reflection by a quasi-periodic layered semiconductor structure, Physica B: Physics of Condensed Matter, 406, 1415-1419.

https://doi.org/10.1016/j.physb.2011.01041

Shi, C., Yuan, J., Luo, X., Shi, S., Lu, S., Yuan, P., Xu, W., Chen, Z., \& Yu, H. (2020). Transmission characteristics of multistructure bandgap for lithium niobate integrated photonic crystal and waveguide, Optics Communications, 461, 125222 .

https://doi.org/10.1016/j.optcom.2019.125222

Singer, A. M., Heikal, A. M., El-Mikati, H., Obayya, S. S. A. \& Hameed, M. F. O. (2020). Ultra-low loss and flat dispersion circular porous core photonic crystal fiber for terahertz waveguiding, Applied Computational Electromagnetics Society Journal, 35, 709-717.

Sun, H., Huang, S., Wang, Q., Wang, S. \& Zhao, W. (2019). Improvement of unidirectional focusing periodic permanent magnet shear-horizontal wave electromagnetic acoustic transducer by oblique bias magnetic field, Sensors and Actuators A: Physical, vol. 290, pp. 36-47, May 2019.

https://doi.org/10.1016/j.sna.2019.03.003

Sung, S.-Y., Sharma, A., Block, A., Keuhn, K. \& Stadler, B. J. H. (2011). Magneto-optical garnet waveguides on semiconductor platforms: Magnetics, mechanics, and photonics, Journal of Applied Physics, 109, $07 \mathrm{~B} 738$.

https://doi.org/10.1063/1.3556781

Trzaskowska, A., Hakonen, P., Wiesner, M., \& Mielcarek, S. (2020). Generation of a mode in phononic crystal based on 1D/2D structures, Ultrasonics, 106, 106146.

https://doi.org/10.1016/j.ultras.2020.106146 
Wang, H., Chen, Y. \& Huang, C. (2019). The electromagnetic waves propagation characteristics of inhomogeneous dusty plasma, Optik - International Journal for Light and Electron Optics, 196, 163148.

https://doi.org/10.1016/j.ijleo.2019.163148

Wei, D., Cao, F., Wu, Z., Liu, Y., Wang, J., Wang, Q., Liu, X. \& Zhang, Q. (2021). Enhanced spectral splitting in a novel solar spectrum optical splitter based on one dimensional photonic crystal heterostructure, Journal of Materiomics, 7, 648-655.

https://doi.org/10.1016/j.jmat.2020.10.014

Zhang, Y., Cao, Z., Lu, G., Zeng, D., Li, M., \& Wang, R. (2018). Reconfigurable array designed for directional EM propagation using energy band theory of photonic crystals, Applied Computational Electromagnetics Society Journal, 33, 1209-1216. 